Discussion Paper No. 14-129

\title{
Susceptibility and Influence in Social Media Word-of-Mouth
}

Jörg Claussen, Benjamin Engelstätter, and Michael R. Ward

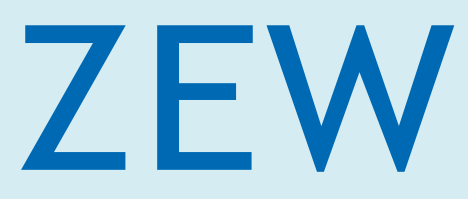

Zentrum für Europäische Wirtschaftsforschung $\mathrm{GmbH}$ Centre for European Economic Research 
Discussion Paper No. 14-129

\section{Susceptibility and Influence in Social Media Word-of-Mouth}

Jörg Claussen, Benjamin Engelstätter, and Michael R. Ward

Download this ZEW Discussion Paper from our ftp server:

http://ftp.zew.de/pub/zew-docs/dp/dp14129.pdf

Die Discussion Papers dienen einer möglichst schnellen Verbreitung von neueren Forschungsarbeiten des ZEW. Die Beiträge liegen in alleiniger Verantwortung der Autoren und stellen nicht notwendigerweise die Meinung des ZEW dar.

Discussion Papers are intended to make results of ZEW research promptly available to other economists in order to encourage discussion and suggestions for revisions. The authors are solely responsible for the contents which do not necessarily represent the opinion of the ZEW. 


\title{
Susceptibility and Influence in Social Media Word-of-Mouth ${ }^{\S}$
}

\author{
Jörg Claussen \\ Copenhagen Business School \\ Benjamin Engelstätter \\ Hochschule Darmstadt and ZEW Mannheim \\ Michael R. Ward \\ University of Texas in Arlington and ZEW Mannheim
}

December 2014

\begin{abstract}
:
Peer influence through word-of-mouth (WOM) plays an important role in many information systems but identification of causal effects is challenging. We identify causal WOM effects in the empirical setting of game adoption in a social network for gamers by exploiting differences in individuals' networks. Friends of friends do not directly influence a focal user, so we use their characteristics to instrument for behavior of the focal user's friends. We go beyond demonstrating a large and highly significant WOM effect and also assess moderating factors of the strength of the effect on the sender and receiver side. We find that users with the most influence on others tend to be better gamers, have larger social networks, but spend less time playing. Interestingly, these are also the users who are least susceptible to WOM effects.
\end{abstract}

Keywords: Word-of-Mouth, Peer Effects, Adoption, Social Networks, Video Games

JEL Code: D85, L14, M31

\footnotetext{
$\S^{\S}$ We gratefully acknowledge support by the ZEW research program Strengthening Efficiency and Competitiveness of the European Knowledge Economies (SEEK) financed by the state of Baden-Württemberg. We thank the participants of the corresponding SEEK workshop in Mannheim.

Corresponding author: Michael R. Ward, University of Texas at Arlington, Email: mikeward@uta.edu.
} 


\section{Introduction}

Understanding the flow of information within social networks becomes more and more important. This is partly due to the increasing ability to measure information flows within Internet mediated networks but also due to new possibilities in developing more effective Wordof-Mouth (WOM) marketing campaigns (Kozinets et al. 2010). In general, WOM describes the process of the transmission of information from person to person in form of personal conversation or, increasingly, electronically as in online consumer reviews, blogs, emails or private messages in online social networks. Marketers and sociologists have recognized the importance of WOM already long before the Internet, proposing that informal unsolicited WOM affects the majority of all purchase decisions (Brooks 1957, Dichter 1966).

With the more recent advent of online consumer reviews such as product ratings or product recommendation in blogs, information relating to WOM has become more easily observable and traceable. Every consumer is a potential source of WOM information that is available to potential purchasers. Easily observable WOM information displayed in recommendation systems and reviews form the basis of a growing understanding of how WOM affects product sales. Less well known is the role of more intimate or personal WOM such as recommendations in personal conversations or communications. This is likely to be remedied by the growing availability of granular data from online social media.

Peer recommendations can be especially important for experience goods that feature greater product quality uncertainty. This is particularly true for entertainment goods because there is a constant flow of new products with unknown product features on both horizontal (e.g. genre) and vertical (e.g. quality) product characteristics. Marketing campaigns are being designed that exploit the ability to generate more and better peer recommendations. For example, 
a WOM marketing campaign may seek to target "seed" key adopters who have relatively more influence within their social networks so as to increase the likelihood of a purchase by those who are more susceptible to such influence. Identifying the characteristics that lead to more influence or susceptibility would be key to implementing such a campaign.

Inferring causal peer effects from an estimation procedure is fraught with many challenges. Broadly defined, there are two common approaches. With randomized control trials, such as Aral \& Walker (2012) the researcher provides exogenous stimulus to a subject and observes how this stimulus affects the subject's peers. Causality derives from the exogenous and randomized stimulation. However, in a social context, care must be taken to prevent the control group from 'infecting' themselves with the stimulus in ways that could bias estimates. While observational data, such as we use, is more available, causal inferences are based on the ability of the estimator to control for potential sources of bias. The common threat to identification is the selection of both the focal user and her local network into the treated group due to shared, but unobserved, characteristics, i.e., homophily (Bramoullé et al, 2009). Below, we will adapt these methods to our application.

We examine the flow of product information in form of peer recommendations within a social network of video gamers. In particular, we identify WOM information as a 'peer effect' from the purchase decisions of a focal user's friends to the focal user's purchase decision. Because our context includes nearly 100,000 individuals and 150 video game launches, we observe considerable variation in the magnitude of the peer effect across senders and receivers of WOM information and across game characteristics. This allows us to identify which factors generate larger or smaller WOM effects. 
Our results show a large and highly significant impact of the WOM peer effect on the focal user's decision to adopt a particular game. We document a diminishing marginal effect of WOM from a larger share of the focal user's friends adopting the game. The users with the most influence tend to be better gamers (i.e., accumulate more in-game awards), who send fewer signals (i.e., spend less time playing) and who have larger local networks. The most susceptible users tend to be the opposite; they are of lower ability, play often, and have smaller social networks. That is, the attributes that lead a user to have more influence in a WOM setting are precisely the attributes that lead them to be less susceptible to WOM information.

The remainder of the paper is organized as follows. In section 2 we provide a condensed overview of the literature explaining WOM and its effects. In the following section we explain the econometric challenges in the identification of peer effects and our approach to achieve identification. Section 3 introduces our empirical model. Section 4 presents the data and is followed by section 5, presenting the empirical results. Finally, section 6 concludes.

\section{Previous Literature on Word-of-Mouth}

WOM describes the process of conveying information from person to person and plays a key role in each consumer's buying decisions (Richins and Root-Shaffer 1988, Jansen et al. 2009). The information exchange in form of WOM also influences consumer's attitude and behaviors (Brown and Reiningen 1987, Gilly et al. 1998) as well as brand awareness or product knowledge. Overall, WOM can be transmitted in several forms, e.g. in personal conversation or electronically as in online consumer reviews, blogs, emails, instant messaging or private 
messages in online social networks, reaching many other consumers or institutions simultaneously via the Internet (Hennig-Thurau et al. 2004).

WOM in form of blogs as well as in recommendation systems, such as Yelp!, Booking.com, Amazon ratings, or even the Oprah book club are easily observed and so have been the basis of studies examining their effects in the market for books (Chevalier and Mayzlin 2006, Carmi et al. 2010), movies (Liu, 2006, Zhang and Dellarocas 2006, Duan et al. 2008), and video games (Zhu and Zhang 2010). Overall, the empirical evidence obtained to explain the relationship between online consumer reviews and sales is mixed. On the one hand, several studies (i.e. Chevalier and Mayzlin 2006, Zhang and Dellarocas 2006, Zhu and Zhang 2010) find positive impacts. On the other hand, however, online reviews might as well serve as mere predictors that do not influence sales (Chen et al. 2004, Duan et al. 2008). For blogs, Kozinets et al. (2010) show that WOM does not simply increase or amplify marketing messages but alters content and meaning when embedding information in the community.

Refraining from information available to the entire public we focus on more intimate recommendations such as song recommendations from audiophile friends, textbook adoption decisions based on colleagues' input, and video game recommendations from online team members. Some past research has noted the importance of such brand recommendations in 'tweets' (Jansen et al. 2009), that a consumers' engagement in social networks for purchase decisions is moderated by different cultural contexts (Chu and Choi 2011), and that sender/receiver characteristics (tie strength, trust, influence, homophily) are likely to mediate WOM effects (Chu and Kim 2011). As far as we know, only Aral and Walker (2012) have identified characteristics and network structure tied to influence and susceptibility in social networks. Their results indicate that influential individuals are less susceptible to influence 
themselves. While Aral and Walker (2012) run a randomized experiment to identify peer effects, our identification relies on behaviors within the social network structure. We explain our identification in detail in the following methodology section.

\section{Methodology}

\section{A. Peer effects: endogenous, exogenous and correlated effects}

Identifying peer effects requires disentangling three different effects to explain how neighbors' outcomes affect the focal user's own outcome. These are: 1) the endogenous effect, or the influence of peer outcomes, 2) the exogenous peer effect, or the influence of exogenous peer characteristics, and 3) the correlated effects, stemming from individuals in the same reference group tending to behave similarly because they are alike or face a common environment (Bramoullé et al. 2009). Distinguishing the exogenous and the endogenous from correlated effects empirically can be difficult (Manski 1993). Randomized Control Trials (RCTs) have been implemented so as to eliminate any correlated effects (Sacredote 2001, Zimmerman 2003). But even without correlated effects simultaneity in behavior of interacting agents, the reflection problem, introduces a perfect collinearity between the expected mean outcome of the group and its mean characteristics, precluding the identification of separate endogenous and exogenous effects (Bramoullé et al. 2009).

A method for resolving the reflection problem and identifying the endogenous from the exogenous peer effects has been proposed by Bramoullé et al (2009). For this method the network has to allow for overlapping but non-identical peers. Overall, a node's neighborhood outcome is endogenous in explaining the focal nodes' outcome but may be instrumented by 
extended neighborhood effects, so called excluded peers (De Giorgi et al. 2010). ${ }^{1}$ This allows the researcher to relate variation in otherwise similar network members' outcomes to variation in exposure due to variation the composition in their social networks. Still, if the researcher observes only incomplete networks, this method may lead to biased estimates of causal effects (Chandrasekhar and Lewis 2011). ${ }^{2}$

\section{B. Peer effects in our empirical setting}

Our application introduces additional challenges to identification of causal effects in networks and proposes potential solutions to these challenges. In our application the focal user is subjected to the endogenous peer effect as he infers information about the value of adopting a particular video game from information about the adoption decisions of his peers. He is also more likely to adopt a video game when his peers display certain characteristics associated with adoption regardless of whether these peers adopt or not. In most other applications, these characteristics are not affected by adoption decisions so their effect is usually referred to as the exogenous peer effect. In our application, however, the peer characteristics evolve through experience with multiple adoption decisions resulting in neither focal user characteristics nor peer characteristics being time invariant. As gamers adopt and play games, they develop skills and affinities for certain game attributes. Peer characteristics continuously evolve for two reasons. First, a user's network evolves to include more homophilic or in some cases more

\footnotetext{
${ }^{1}$ As an example consider nodes $i, j$, and $k$. Assume that $i$ and $j$ as well as $j$ and $k$ are connected but there is no connection between $i$ and $k$. Accordingly, $k$ affects $j$ endogenously, i.e. with its outcome, and exogenously, i.e. through its characteristics. However, $k$ affects $i$ only through $j$. Therefore, $k$ 's characteristics may be used to instrument the endogenous effect of $j$ 's outcome on $i$ 's outcome. Bramoullé et al. (2009) provide conditions for formal identification which is based on intransitive trials.

${ }^{2}$ Chandrasekhar and Lewis (2011) show that if the available network data are not complete censes but samples out of existing networks they will face measurement error due to non-observed missing links resulting in biased estimates. Our available data, however, are a complete census of the Raptr community network and we therefore are unlikely to miss any links. However, Raptr itself is a sample out of all gamers as it is as itself not mandatory for gaming activity. In addition, we cannot exclude the possibility that gamers do communicate with their peers outside of Raptr. Nevertheless, we suspect the measurement error to be negligible small in our given data.
} 
different peers. Second, even if the network is fixed, the shared experience of playing games together in the past will make measured preference characteristics more similar. Since peer and focal user characteristics are likely to evolve together, neither are likely exogenous to the focal user's adoption decisions.

We adopt several measures to try to overcome this issue of endogeneity. First, following Bramoullé et al. (2009) and De Giorgi et al. (2010) we instrument for peer adoption decisions from non-identical, overlapping groups. As the shared experience of playing games together in the past will make measured preference characteristics more similar, we can use measured preference characteristics from the members of the focal user's network of friends-of-friends who are not friends themselves (G2) as instrumental variables for the adoption decisions of his network of friends (G1). This is intended to isolate the effect of the shared experience of playing games together with members of the G2 network from the shared experience with the focal user itself.

Second, we measure all of our characteristic information prior to the release of the game under investigation. Users will often adopt a game some days after a game is released. In the interim, both the focal user's and his peers' measured preference characteristics will continue to evolve. It is possible that the way that they co-evolve is affected by the release of the game under consideration. To avoid this specific confounding problem, we calculate characteristic values for the focal user, his network of friends G1 and his network of non-overlapping friends-of-friends G2 as of the game's release date and not at a time in which the game could have affected the preference characteristics. 
Third, because we observe multiple game adoption decisions for each user, we can include fixed effects for users and for games. Thus, parameter identification comes from deviations in measures across game adoption decisions. The characteristics we measure are associated with user preferences for different types of games. To the extent that underlying preferences are time invariant, the likely source of this variation would be through adapting to peer preferences - exactly what we wish to measure.

\section{Empirical Model}

In order to identify the magnitude of peer effects across senders and receivers of WOM information we explain the adoption decision of individual $i$ by the peer effects he is subjected to due to the adoption and characteristics of his peer $j$ for a particular game $g$. Therefore we estimate the following equation:

(1) $Y_{i g}=\beta E\left[Y_{j g} \mid j \in G 1_{i g}\right]+\gamma E\left[X_{j g} \mid j \in G 1_{i g}\right]+\delta X_{i g}+C V+u_{i g}$,

where $Y$ is the a dummy indicating the adoption of game $g$ by either individual $i$ or $i$ 's peer $j$ and $X$ is the vector of individual characteristics of either $i$ or $j$ related to game $g . u$ is the typical normally distributed iid error term and $C V$ is a vector of control variables including individual and game fixed effects. The endogenous peer effect which $i$ is subjected to due to the adoption of game $g$ by his friend $j$ is captured in $\left[Y_{j g} \mid j \in G 1_{i g}\right]$. Accordingly, $\left[X_{j g} \mid j \in G 1_{i g}\right]$ captures the exogenous effect $i$ is subjected to due to the characteristics of his friend $j$. We use the share of all of $i$ 's peers, i.e. all of $i$ 's G1 members, who adopted the game $g$ prior to $i$ for the endogenous effect and the average peer characteristics to measure the exogenous effect. We rely on fixed effects instrumental variable panel estimations with fixed game and user effects for inference and 
instrument the endogenous effect of $i$ 's peers on $i$ as explained above with the characteristics of $i$ 's G2 members. We explain all variables in detail in the next section introducing our data.

Although the dependent variable in equation (1) is an indicator variable suggesting a binary choice estimator such as probit or logit we instead rely on a simple Linear Probability Model (LPM) estimator for inference. We adopt the LPM for three reasons. First, non-linear estimators are computationally burdensome with three million observations and the number of parameters implied by two-way fixed effects. Second, the computational burden is exasperated with an instrumental variables Probit estimator. Third, with so many fixed effects, we suffer from the 'incidental parameters bias' (Lancaster, 2000). The LPM produces consistent coefficient estimates but may underestimate standard errors. In our application, the large number of observations leads the calculated standard errors to be quite small. Even if the correct standard errors were many multiples, we would still be confident in most of our tests.

\section{Data}

We obtained user data from the Raptr ${ }^{3}$ platform for the period from January 2010 to November 2011 for about 200,000 distinct users. Raptr is the leading online social network community for gamers with up to 22 million users in 2014 (March). It offers several services for gamers that are available in-game, on the web, and on mobile devices. Each Raptr user can link her console or PC to the Raptr client, thereby receiving an individual profile in the social network that tracks all her gameplay activity for each individual game. Users can link to each other - "friend" each other - to communicate within a common social circle. Raptr offers a

\footnotetext{
${ }^{3}$ See www.raptr.com
} 
condensed personalized news feed aggregating interesting discussions, news, videos, screenshots, and strategy guides based on the games the user, or his linked social circle, are currently playing. The Raptr client provides useful in-game features to gamers such as crossplatform IM chat, web surfing, access to popular social media services as well as video and screenshot capturing that all facilitate the coordination of gameplay. WOM can be facilitated through the Raptr platform in multiple ways: first, the Raptr client displays which games are currently played by friends, second, gaming activity of friends is displayed in the news feed, and third, the chat client can be used to talk with friends about their new games. So users of Raptr are frequently exposed to game adoption decisions of their online friends, creating a potentially strong WOM channel and making the Raptr community a well-suited empirical context for studying WOM. In our overall data we observe 37 million gaming sessions by 195,337 distinct users. For illustration, Figure 1 pictures a Raptr profile page for a typical user giving an overview of all the information we have available for every user.

\section{A. Sample Creation}

The creation of the sample on which we test our hypotheses is driven by some unique features of the Raptr data. We follow a user's gaming activity and 'friending' behavior over time. At the same time, there is a regular flow of new games being released from which Raptr users make adoption decisions. We observe that, over the course of a month, or even a week, gamers tend to: play older games out of their inventory, purchase and play a newly released game and choose not to purchase and play a different newly released game. Most users concentrate their game playing among games that have been recently released and purchased. We wish to focus upon the decision to purchase and play a newly released game and the factors that affect this decision. 
We start by defining a sample of popular games released during our sample period. We identify the 263 games that have at least 1,000 adoptions. Of these, complete game information was obtainable for 150 games (i.e, verified release dates and measures of game quality).

We next define game adoptions and the set of Raptr users who are 'at risk' to adopt the game. Since gamers join Raptr at different times, we do not observe game adoption decisions made before they joined. Some gamers join Raptr, experiment and then abandon the site while others have spells of inactivity between spells of regular activity. For our analyses, a game adopter is defined as a user if we observe that they began playing the game within 90 days after the game was released. The set of non-adopters include those who do not play the game within 90 days but have played some other game during this period. Thus, we do not include inactive Raptr users among non-adopters. We also observe some game play by a few users prior to game release, usually by one to twelve months. These tend to involve a small number of users who appear to be beta testers for the game. As such, they do not fit the model of peer effects through word-of-mouth and they are not included among either the adopters or the non-adopters. Figure 2 depicts the days from game release to game adoption for adopters. It appears that more than $70 \%$ of all game adoptions occur within our 90 day window.

We use detailed information on social link formation, i.e. "friending," to create our network measures. The Raptr data records the date and time when any two users form a link. For each game in the sample and for both adopter and non-adopters of the game, we create two different sets, the network of friends, $\mathrm{G} 1_{\mathrm{ig}}$, and his network of friends-of-friends who are not friends, $\mathrm{G} 2_{\mathrm{ig}}$. For each adoption decision, we take all links made prior to the game's release and omit links made later, even those made during the 90 day adoption window. The goal is to only use the pre-determined friendship network and exclude friendships that might result from the 
adoption of this game. Using the date that a link was formed means that the same user facing another game adoption decision at a later date will usually have a different $\mathrm{G} 1_{\text {ig }}$ and $\mathrm{G} 2$ ig for different games because new links can be formed between the two games' release dates.

The sample created by this process is large. We are left with nearly 100,000 distinct users facing 3.2 million game adoption decisions. These users have over 1 million friends, G1, and 10 million friends-of-friends, G2. For each game adoption decision, we calculate the share of members of the focal user's G1 network who adopted the game before him as our main explanatory variable capturing peer effect WOM. Note that we do not observe communications between users such as online messages via Instant Messaging tools or emails or personal meetings of users.

\section{B. User Characteristics}

For each user, we have created measures of user characteristics for each game adoption decision. These use only game playing information up to the time of the adoption decision. This way, they are predetermined from the point of view of the game adoption decision and less likely to be affected by the adoption decision itself. Along with the focal user's characteristics, we generate the average values for G1 and G2 of adoption decisions and all characteristics. These user characteristics measure five separate dimensions of gamer preferences or human capital, which we each explain in detail below.

1. A measure of user's preference for a type of game is developed from industry genre categories. For all gaming sessions occurring prior to a game's release, the hours spent in each genre are aggregated. This measure, sharegenre $_{i g}$, is defined as the fraction of a user's past playing time spent in this game's genre category. This varies over adoption decisions both 
because the games in question are from different categories and because the user may gain more experience with different genres over time. Six broad gaming categories, "Strategy," "Shooter," "Action," "Role Playing," "Sports," and "Casual" are defined based on over 120 finer descriptions of genres included in Raptr. Over all users, the largest category was "Shooter" with $44 \%$ while the smallest was "Casual" with $5 \%$.

2. Another user preference measure is constructed for console platforms. For all gaming sessions occurring prior to a game's release, the hours spent in each game on each console are aggregated. This measure, shareplatforme $i g$, is defined as the fraction of a user's past playing time spent on the platform this game was released on. Possible platforms included XBOX, PlayStation, Wii, or computer. However, in our available time period, the Raptr client was unable to track PlayStation activity. The Wii activity on Raptr was quite small. As a consequence, $80 \%$ of our measured activity is on the $\mathrm{XBOX}$ while $18 \%$ was with computer games.

3. A third measure of a user's preference is similarly developed for a game's maturity of content level from industry "age appropriateness" categories. For all gaming sessions occurring prior to a game's release, the hours spent in each category are aggregated. This measure, $\operatorname{shareESRB}_{i g}$, is defined as the fraction of a user's past playing time spent in this game's maturity category. The ESRB designates each game introduced in the US as one of E, E10+, T, M or AO for "Everyone," "Everyone aged ten or older," "Teens," "Mature audiences" or "Adults Only." Since none of the games in our sample were rated AO we drop this category. However, some are not rated, usually because they are not introduced in the US, and fall into a fifth "other" category. About 57\% of all game play was "Mature," with 21\% "Teen" and less than $10 \%$ for each of the others. 
4. We feature two measures of human capital. The first, "gaming intensity" is calculated as a gamer's average number of minutes spent playing video games per week. Information about what game a user is playing and how well he is doing will appear in his peers' "newsfeeds" more often when they spend more time playing. This would be akin to a more active Facebook friend generating more posts in one's newsfeed. Figure 3 depicts the distribution of the logarithm of the gaming intensity across users.

5. As a second measure for human capital, an "award score" is created from the various awards and achievements gamers unlock through game play. This is meant to measure player ability. We develop a cardinal measure between 0 and 1 for each award earned in a game by calculating the percentile of the game's adopters who earn this award. For example, if all $100 \%$ of gamers earn an award for completing an initial tutorial, we would assign them each the lowest percentile value of 0 . If another award is earned by only $14 \%$ of game adopters, we would assign a value of 0.86 to the user. We take the average of these measures over the games that the user has played. Figure 4 depicts the distribution of award scores across users.

These measures are calculated for different groups of individuals and at the time of each game release event. Each of these variables are calculated for each focal user $i$, her immediate social network $\mathrm{G} 1_{i g}$, and for her "second degree" network $\mathrm{G} 2_{i g}$. Moreover, a Raptr user can have 150 separate values of these variables if she was active in the network for all 150 game releases. Summary statistics for each of these groups are reported in table 1 . Notice that a typical user will only adopt $3 \%$ to $4 \%$ of games available to her. 


\section{Empirical Results}

\section{A. Baseline Results}

In order to identify the impact of peer effect WOM on game adoption we test two separate specifications. Table 2 reports the key results for our baseline regression. The vector $X$ includes share of time spent in the game's genre, platform, and ESRB rating, gaming intensity, award score and network size. The separate columns report both the first- and second-stage regression results. In the second-stage regression, values of $X$ for both the focal user and for members of $\mathrm{G} 1_{\mathrm{ig}}$ are included. In the first-stage regression, values for members of $\mathrm{G} 2_{\mathrm{ig}}$ are also included. Regressions also include fixed effects for each game and each user. These two-way fixed effects imply that the $X$ variables capture the change in the values for an individual between game releases. Our variable of interest is the share of $\mathrm{G} 1_{i}$ who adopted the game which is highlighted in red.

The first-stage results generate a few consistencies. Gaming intensity and award score are not significant for the $\mathrm{G} 1_{i}$ and $\mathrm{G} 2_{i}$ users. Time spent playing games with the focal game's genre, platform, and ESRB rating all increase the fraction of $\mathrm{G} 1_{i}$ adopting the focal game. This is true for values constructed from the focal user, the $\mathrm{G} 1_{i}$ users and the $\mathrm{G} 2_{i}$ users. The consistent patterns across the three groups may reflect a degree of homophily between these groups. As indicated above, the $\mathrm{G} 2{ }_{i}$ variables are excluded in the second stage. Thus, the statistically significant coefficient estimates for the $\mathrm{G} 2{ }_{i}$ variables indicate that variation in the endogenous peer effect (or WOM effect) is not under-identified.

Estimated values in the second-stage generally conform to expectations. The estimated WOM effect is 1.41 , indicating that, at the margin, a $1 \%$ increase in the share of $\mathrm{G} 1_{\mathrm{i}}$ who adopt the game increases the focal user's probability of adopting by $1.4 \%$. In addition, an increase in 
the focal user's exogenous characteristics, time spent playing games with the focal game's genre, platform, or ESRB rating, increases the probability of adopting. The adoption probability decreases with the award score, gaming intensity and network size. However, holding the endogenous WOM effect constant, the exogenous characteristics for peers among $\mathrm{G} 1_{\text {ig }}$ members tend to have the opposite sign. ${ }^{4}$

\section{B. Diminishing Returns to WOM}

Another concern is the magnitude of the estimated WOM effect. A value greater than one is implausible for a global value. It implies an explosive feedback as an exogenous $1 \%$ increase in adoption for a user induces a 1.4\% increase among her G1 network members, a $1.96 \%\left(1.4^{2}\right)$ increase among her G2 network members, and so on. While this may be a marketer's dream, it may be an artifact of our specification and this coefficient value may not hold at all levels of the WOM peer effect. Table 3 indicates that, on average, for $89.8 \%$ of focal users, no members of $\mathrm{G} 1_{\text {ig }}$ will have adopted the game. The informational content of at least one member adopting the game is likely to be greater than the additional informational content of subsequent adoptions. That is, we might expect a diminishing marginal effect of WOM as a greater share of the people in the focal user's network adopts the game. As the focal user becomes aware of more members of her network using the product, the marginal informational content conveyed about the product is still positive but of diminishing importance.

To test this, we alter our WOM measure to dummy variables for the fraction of $\mathrm{G} 1_{\mathrm{ig}}$ adopting the game. First, instead of measuring the endogenous WOM peer effect with the fraction of $\mathrm{G} 1_{i}$ adopting the game, we estimate a specification in which we use a dummy variable

\footnotetext{
${ }^{4}$ In specifications in which adoption by G1 members is omitted, the estimates of the coefficients of the characteristics of G1 members are positive.
} 
for the $10.2 \%$ percent of observations in which any member of $\mathrm{Gl}_{i}$ adopted the game. Next, we estimate a specification that decomposes this dummy variable based on the median number who adopts the game. In about half of the times that a member of $\mathrm{G} 1_{i}$ adopts the game, fewer than 0.273 will adopt it and in half of the time more than 0.273 will adopt it (see table 3 ). We include with two dummy variables - one if the fraction adopting is below the median and one if this fraction is above the median. We hypothesize that the effect of each adoption from a larger fraction of $\mathrm{G} 1_{i}$ members adopting the game will have a smaller effect on the focal user.

Table 4 reports the first of these specifications and is analogous to table 2 . In the firststage, time spent playing games with the focal game's genre, platform, and ESRB rating for the focal user, the $\mathrm{G} 1_{i}$ users and the $\mathrm{G} 2_{i}$ users all increase the fraction of $\mathrm{G} 1_{i}$ adopting the focal game. The estimates for award score and gaming intensity are again not consistent across the three groups. The second-stage results are quite similar to those in table 2 . The variable of interest, highlighted in red again, indicates that the focal user is $62 \%$ more likely to adopt a game if any member of $\mathrm{G} 1_{i}$ also adopted it.

Table 5 reports the second specification that decomposes the dummy variable based on the adoption fraction among the focal user's social network. This specification implies two separate endogenous variables and two first-stage regressions. The first- stage regression estimates in columns 1 and 2 follow similar patterns as in tables 2 and 4 . In particular, since the coefficients on the excluded variables from $\mathrm{G} 2_{i}$ characteristics differ enough across the two dummy variables, we can identify independent variation in each one. This is confirmed in column 3 with both endogenous variables entering highly significantly. Moreover, the coefficient estimates of these variables of interest indicate that the WOM peer effect is twice as large when more $\mathrm{G} 1_{i}$ members adopt the game as when fewer adopt (0.3923 versus 0.7696$)$. However, table 
3 indicates that the fraction adopting in the second group is four times as large as the first group ( 0.148 versus 0.595$)$. Thus, the effect per G1 adoptee is half the size when more adopt. This is in line with our expectation of diminishing marginal effects from WOM exposure.

This result may have important implications for WOM marketing campaigns. These campaigns attempt to "seed" a social network with product trials that would not have occurred otherwise so as to generate WOM effects on others. If these seeds are socially distinct from each other, they will have smaller effects on more local social networks. Reaching more distinct G1 networks would increase the reach of the campaign linearly. On the other hand, if they are socially close to each other, they are likely to both be in G1 for some of their "friends." This will generate a larger effect but, all else equal, they will reach fewer distinct G1 networks. Our estimates indicate that the increase in effectiveness within G1 does scale the way that increasing the number of G1 groups does. All else equal, a WOM campaign would tend to be more effective if it targets initial seeds that are not already linked.

\section{Mediators of WOM Magnitudes}

Finally, we investigate how the characteristics of the focal user and her immediate network affect the magnitude of the WOM effect. For example, Aral and Walker (2012) show that various demographic features are associated with network members being more influential or susceptible. Social media marketers have obvious incentives to seek out more influential and susceptible network members so as to stimulate a larger response. Our data do not include demographic features but do include measures of user's past video gaming behavior. Network members may be affected differently depending on how actively they participate in the activity the network is designed to facilitate. 
We test for these effects by estimating the WOM effect for focal users with higher or lower values of measures related to their accumulated human capital. Specifically, we examine three measures related to gaming intensity (hours of game play per week), gaming ability (award score), and network engagement (size of their local network). For example, we examine how the focal user's susceptibility is affected by award score by assigning each focal user to a quintile based on the award score they had achieved prior to this game's release. Define $\phi_{i q}$ as an indicator function equal to 1 if focal user $i$ is in quintile $q$ and equal to 0 otherwise. We estimate five WOM parameters, one for members of each quintile, by interacting the quintile indicator variables with the share of $\mathrm{G} 1_{\mathrm{ig}}$ members adopting the game.

$$
Y_{i g}=\sum_{q=1}^{5} \beta_{q} \phi_{q} E\left[Y_{j g} \mid j \in G 1_{i g}\right]+\gamma E\left[X_{j g} \mid j \in G 1_{i g}\right]+\delta X_{i g}+C V+u_{i g},
$$

Since all five quintile WOM parameters are endogenous, we also generate instruments by interacting the quintile indicator variables with the $X$ variables for the $\mathrm{G} 2$ ig members. One desirable feature of this specification is that each of the five WOM parameter estimates depend only on the values from the quintile and are estimated independently from each other. ${ }^{5}$

Susceptibility results are reported in table 6 and are also displayed in figure 5 . The three columns in the table and three panels in the figure report second-stage regression results for the three different measures of the focal user's past activities.

1. The coefficient estimates for award score form an inverted "U" shape. Users at the low end tend to be new to Raptr and may be wary of information they receive or may not yet know how to incorporate it into their decision making. Users at the higher end tend to be avid gamers and are less reliant on information they receive from others.

\footnotetext{
${ }^{5}$ With quintile interactions for a particular measure, the measure enters regression equation (2) as five quintile dummy variables rather than the underlying continuous variable in equation (1)
} 
2. On the other hand, it is clear that users with more gaming intensity are clearly more susceptible to WOM effects. These gamers have a revealed preference for playing games and are likely to adopt more games. Further, they may seek games that they are more sure more enjoyable when played with members of their network.

3. Finally, it appears that susceptibility falls with the focal user's network size. With a larger local network, a gamer may have more options for a shared game experience within her network. As such, she need not be as easily swayed by adoptions with her network.

We measure influence of the focal user's peers on him similarly. We create quintile indicator variables for each of the three average accumulated human capital measures for $\mathrm{G} 1_{\mathrm{ig}}$. Thus, the top quintile for award score would be associated with users with a local network of high skill gamers. Define $\theta_{i q}$ as an indicator function equal to 1 if focal user $i$ 's network is in quintile $q$ and equal to 0 otherwise.

$$
Y_{i g}=\sum_{q=1}^{5} \beta_{q} \theta_{q} E\left[Y_{j g} \mid j \in G 1_{i g}\right]+\gamma E\left[X_{j g} \mid j \in G 1_{i g}\right]+\delta X_{i g}+C V+u_{i g},
$$

We similarly create instruments based on the values of $X$ for $\mathrm{G} 2_{\text {ig }}$ again calculated prior to the game's release. We interpret the coefficient estimates for these quintiles as the relative influence that network members have based on these measures of their participation level.

Influence results are reported in table 7 and are also displayed in figure 6 . The three columns in the table and three panels in the figure report results for the three different measures of the focal user's past activities.

1. The coefficient estimates for award score are increasing or form a " $U$ " shape. More skilled gamers appear to have more influence than less skilled gamers. 
2. The estimates for gaming intensity are clearly falling for higher quintiles. One interpretation of this is that information from network members who are less active has more weight. Networks in which members are very active may be flooding the focal user with information, which leads the focal users to discount it more. This interpretation aligns well with anecdotal evidence from other social media where users skim or filter out posts from network members who are particularly more active.

3. It appears that influence may increase with the size of the networks of the network members, or with the size of $\mathrm{G} 2$ ig. When network members themselves are part of larger networks, they are likely to receive and evaluate more bits of information. The information that they then pass on to the focal user tends to carry more weight.

One interesting insight from these estimates is that the very thing that makes a network member more influential also makes them less susceptible. The shapes of each of the three measures in figure 6 essentially are inverses of the shapes from figure 5. Not only does influence increase where susceptibility decreases, but it generally increases at an increasing rate where the other decreases at an increasing rate. This would be consistent with network members having more influence because they are known to be less susceptible. When they pass on information, it is expected that the information has been vetted more thoroughly.

These results suggest implications for WOM marketing campaigns. Such a campaign would naturally seek out more influential members as seeds. These would be members who: 1) are better at the activity the network is designed to facilitate, in this case, more skilled gamers with higher award scores; 2) are less active within the network, in this case, with lower gaming intensity; and 3) have larger social networks, as indicated by the effect of the number of links. 
However, these potential seeds are precisely the network members who are hardest to be convinced to adopt through WOM. Presumably they would also be more difficult to seed by other means also. It is not clear if their increased influence more than compensates for their decreased susceptibility.

\section{Conclusion}

There is growing interest in understanding how WOM information flows through social networks. The methods used to uncover these effects are generally classified into Randomized Control Trials (RCTs) on experimental data and Instrumental Variables (IV) estimation based on observational data. RCTs have the advantage in their ability to identify causal relationships. However, there are instances where RCTs may be difficult to implement but where observational data are available. For example, the RCT equivalent to our study would require that all members of the focal user's local network, G1, be a part of the experiment. Otherwise, some members of G1 will endogenously adopt the product and the characteristics that are related to adoption are likely shared between them and the focal user leading to homophily bias. In our case, it seems implausible to be able to restrict game availability to so many avid gamers. Fortunately, with the increased availability of granular data, our IV method has potential applications to other product categories that make use of other social networks.

We are able to glean insights due by exploiting key features of our observational data. First, multiple adoptions allow us to incorporate user fixed effects to reduce unobserved correlation between two users' adoption decisions (e.g., homophily). Second, we observe predetermined characteristics of users that we use to create plausibly exogenous instrumental 
variables. Third, since many of the user gaming characteristics are related to user affinity for the video game products, we are able to examine the effects of these characteristics on information flows.

Our findings indicate a rather complicated role for user affinity. Better gamers with larger networks who are not constantly playing have more influence but are also less susceptible. While these measures are related to general consumer affinity, it is not clear if these findings are product specific or if they will generalize to comparable constructs in other product applications, calling for further studies in related domains. 


\section{References}

Aral, S., and Walker, D. (2012). Identifying Influential and Susceptible Members of Social Networks. Science 337 (6092): 337-341.

Bramoullé, Y., Djebbari, H., and Fortin, B. (2009). Identification of peer effects through social networks. Journal of Econometrics 150 (1): 41-55.

Brooks, R. C. Jr. (1957). 'Word of Mouth’ Advertising in Selling New Products. Journal of Marketing 22 (2): 154-161.

Brown, J. J., and Reingen, P. H. (1987). Social ties and word-of-mouth referral behavior. Journal of Consumer Research 14 (3): 350-362.

Carmi, E., Oestreicher-Singer, G., and Sundararajan, A. (2012). Is Oprah Contagious? Identifying Demand Spillovers in Online Networks. NET Institute Working Paper No. 10-18

Chandrasekhar, A. G, and Lewis, R. (2011). Econometric of Sampled Networks. MIT working paper.

Chen, P.-Y., Wu, S.-Y., and Yoon, J. (2004). The Impact of Online Recommendations and Consumer Feedback on Sales. In: Proceedings of the International Conference on Information Systems, ICIS 2004. Seattle: Association for Information Systems: 711-724.

Chevalier, J. A., and Mayzlin, D. (2006). The Effect of Word of Mouth on Sales: Online Book Reviews," Journal of Marketing Research 43 (3): 345-54.

Chu, S.-C., and Choi, S. M. (2011). Electronic Word-of-Mouth in Social Networking Sites: A Cross-Cultural Study of the United States and China. Journal of Global Marketing 24 (3): 263-281. 
Chu, S.-C., and Kim, Y. (2011). Determinants of Consumer Engagement in Electronic Word-of-Mouth (eWOM) in Social Networking Sites. International Journal of Advertising 30 (1): 47-75.

De Giorgi, G., Pellizzari, M., and Redaelli, S. (2010). Identification of social interactions through partially overlapping peer groups. American Economic Journal: Applied Economics 2 (2): $241-275$.

Dichter, E. (1966). How Word-of-Mouth Advertising Works. Harvard Business Review 44 (6): 147-166.

Duan, W., Gu, B., and Whinston, A. B. (2008). Do Online Reviews Matter? An Empirical Investigation of Panel Data. Decision Support Systems 45 (4): 1007-1016.

Gilly, M. C., Graham, J. L., Wolfinbarger, M. F., and Yale, L.J. (1998). A dyadic study of interpersonal information search. Journal of the Academy of Marketing Science 26 (2): $83-$ 100.

Hennig-Thurau, T., Gwinner, K. P., Walsh, G. and Gremle, D. D. (2004). Electronic word-of-mouth via consumer-opinion platforms: What motivates consumers to articulate themselves on the Internet? Journal of Interactive Marketing 18 (1): 38-52.

Jansen, B. J., Zhang, M., Sobel, K., and Chowdury, A. (2009). Twitter Power: Tweets as Electronic Word of Mouth. Journal of the American Society for Information Science and Technology 60 (11): 2169-2188.

Kozinets, R. V, de Valck, K., Wojnicki, A. C., and S. J. S. Wilner (2010). Networked Narratives: Understanding Word-of-Mouth Marketing in Online Communities. Journal of Marketing 74 (2): 71-89. 
Lancaster, T. 2000. "The incidental parameters problem since 1948." Journal of Econometrics, 95: 391-414.

Liu, Y. (2006). Word of Mouth for Movies: Its Dynamics and Impact on Box Office Revenue. Journal of Marketing 70 (3): 74-89.

Manski, C. (1993). Identification of endogenous social effects: The reflection problem. The Review of Economic Studies 60 (3): 531-542.

Richins, M. L., and Root-Shaffer, T. (1988). The role of involvement and opinion leadership in consumer word-of-mouth: An implicit model made explicit. Advances in Consumer Research 15 (1): 32-36.

Zhang, X. M., and Dellarocas, C. (2006). The Lord of the Ratings: How a Movie's Fate Is Influenced by Reviews. In: Proceedings of the 27th International Conference on Information Systems (ICIS). Milwaukee: Association for Information Systems.

Zhu, F., and Zhang, X. M. (2010). Impact of Online Consumer Reviews on Sales: The Moderating Role of Product and Consumer Characteristics. Journal of Marketing 74 (2): 133148. 
Figure 1: Illustration of a typical Raptr Profile

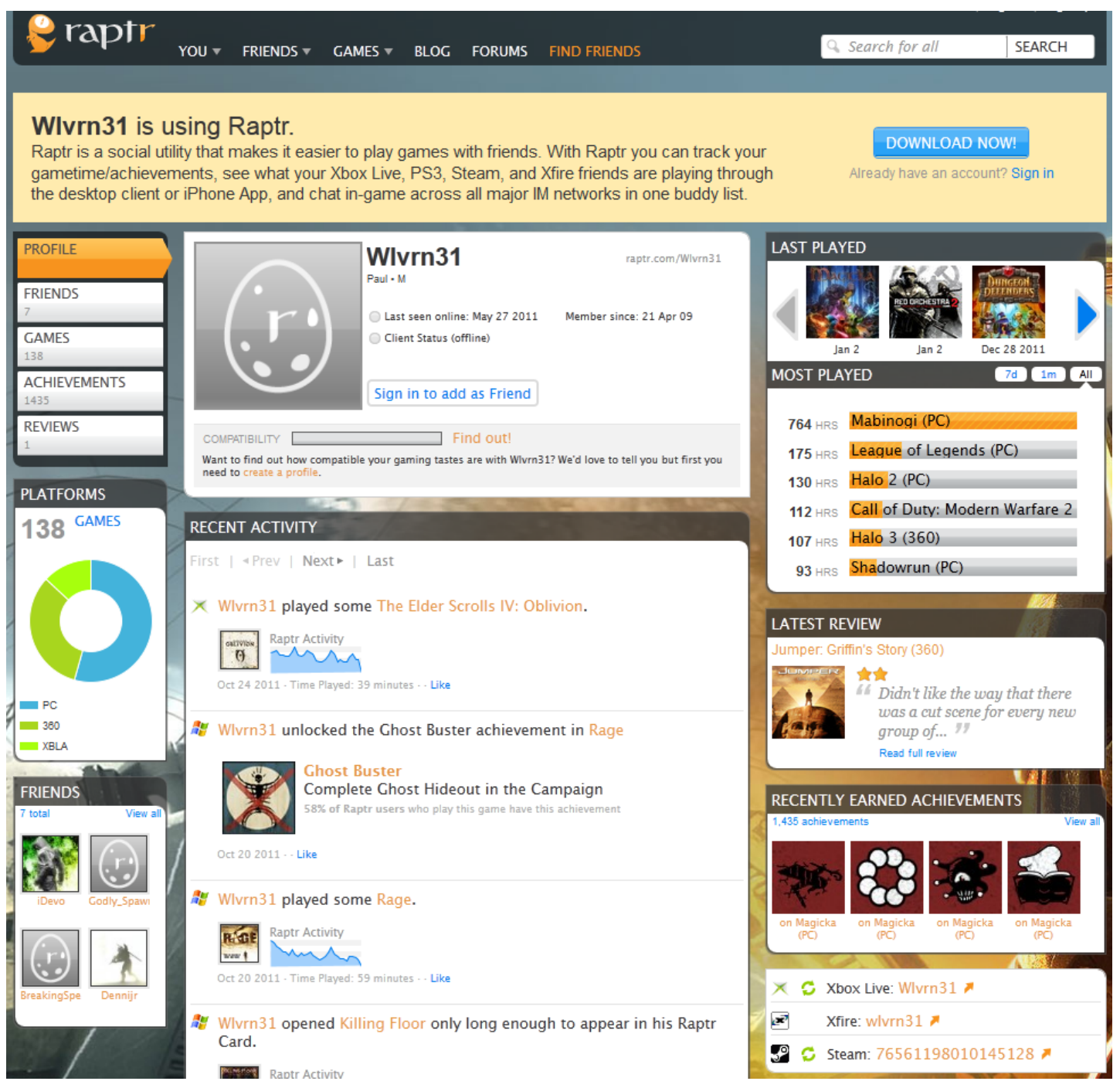


Figure 2: Histogram of days to Game Adoption if less than 150 Days

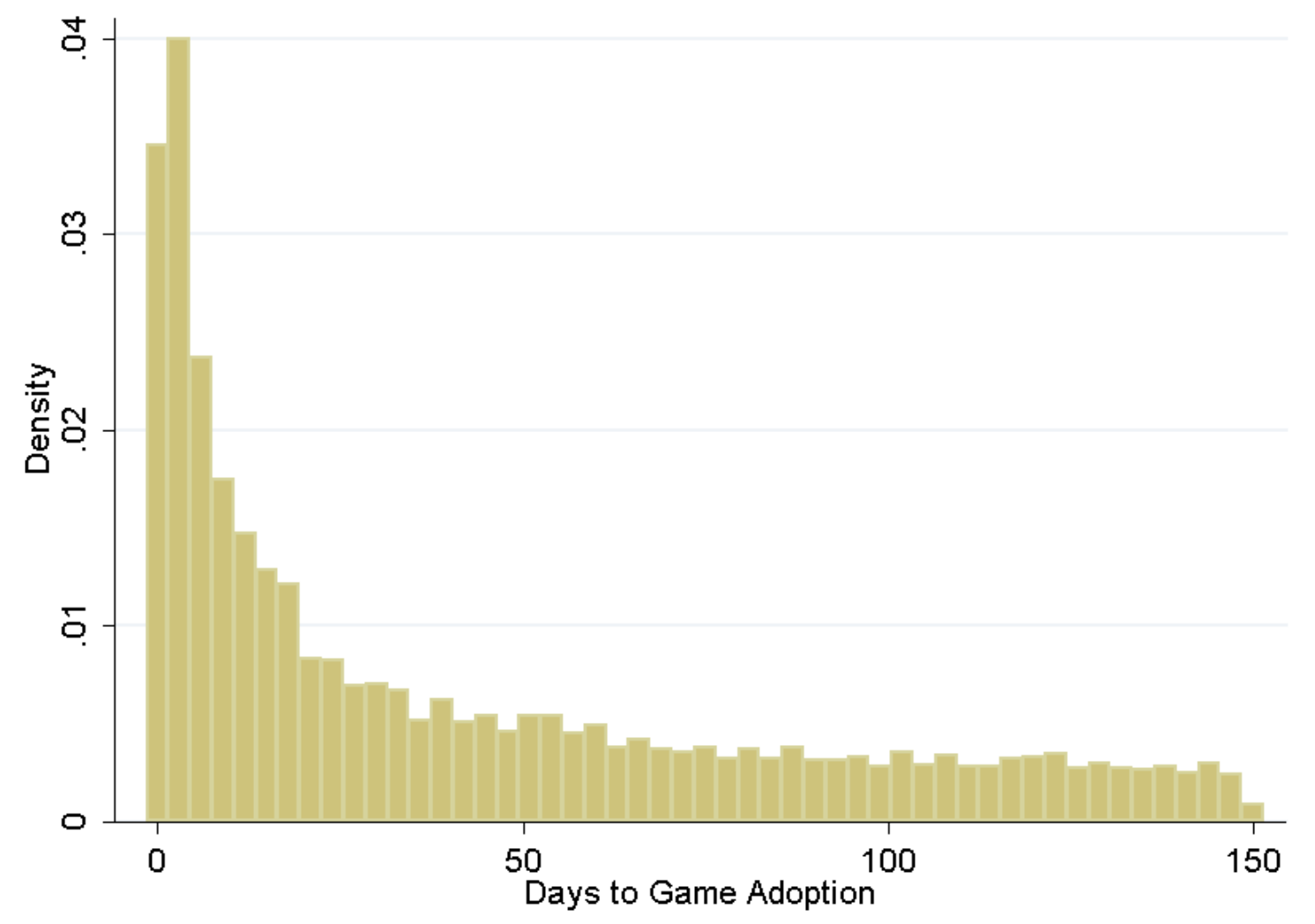


Figure 3: Histogram of Logarithm of Gaming Intensity

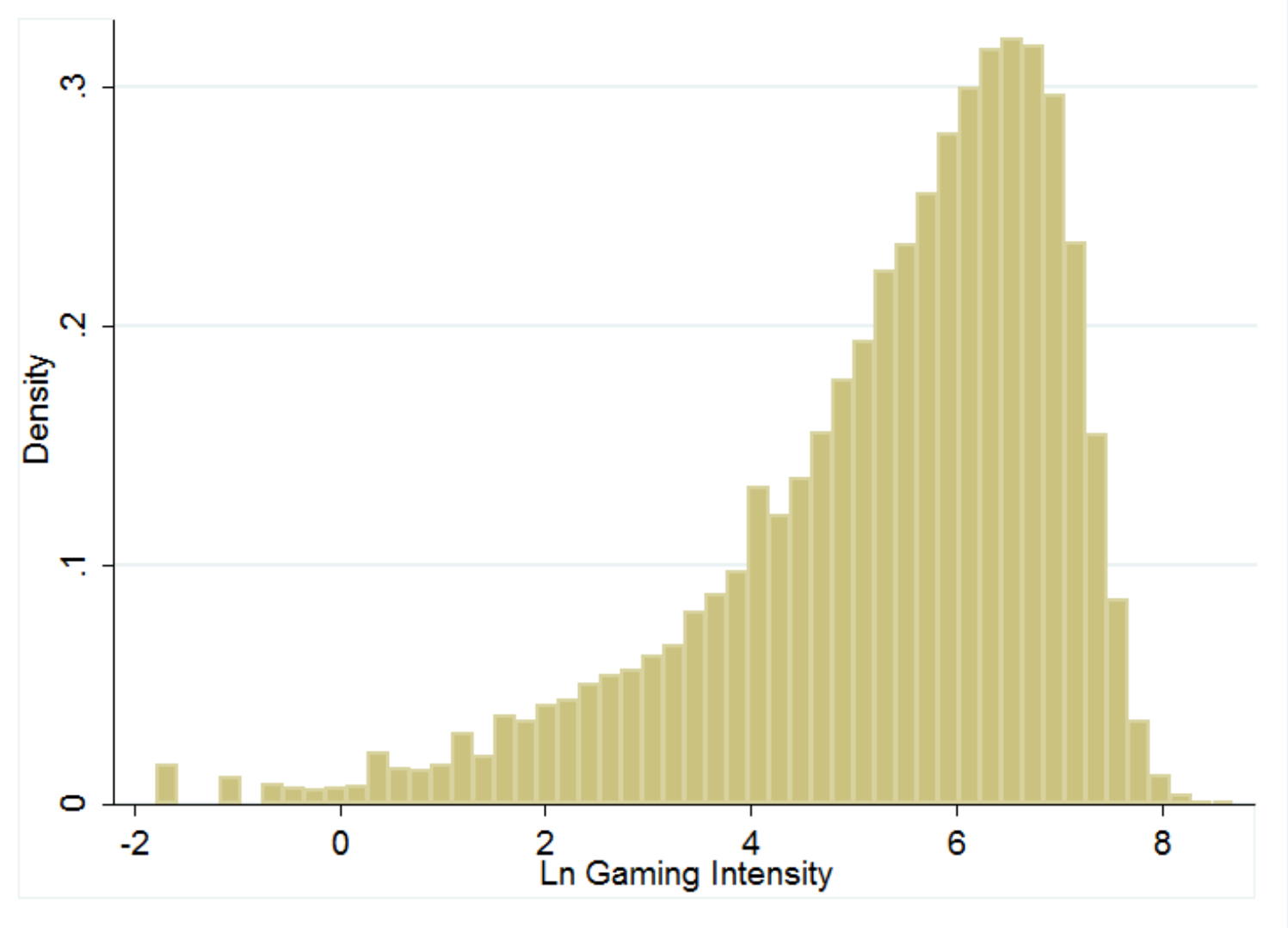


Figure 4: Histogram of Award Score

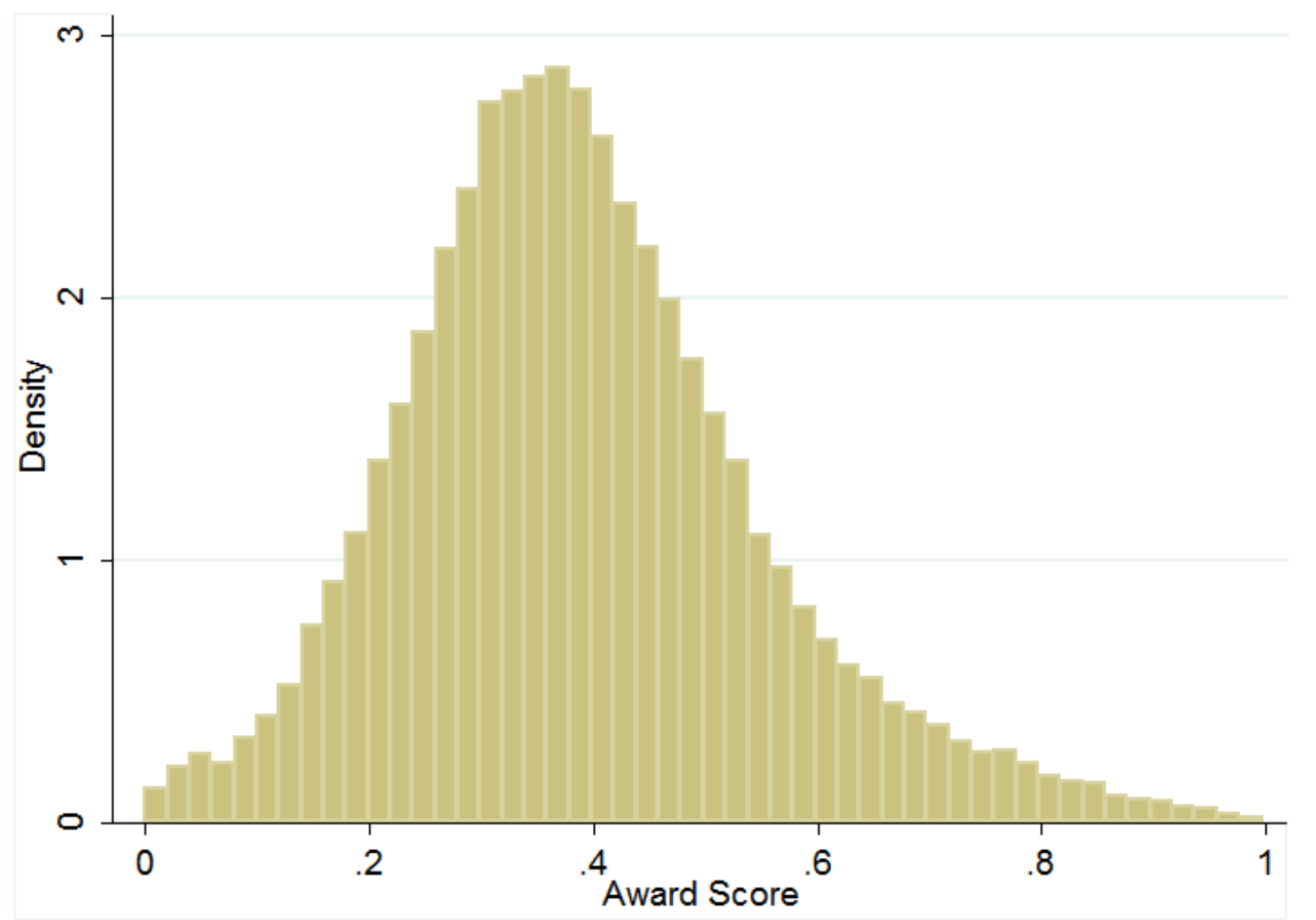


Figure 5: Estimates of Moderators of Word-of-Mouth 'Susceptibility'

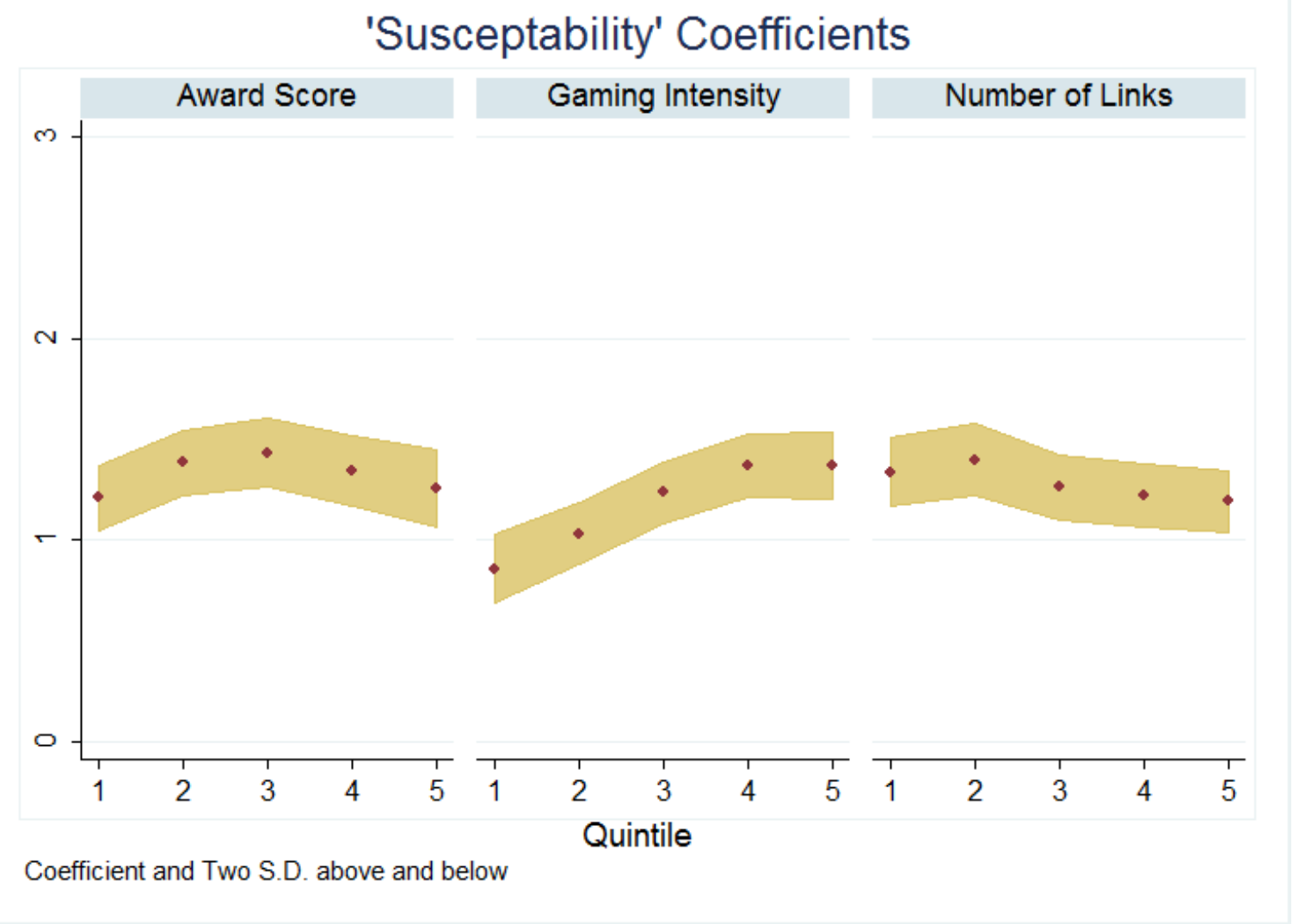


Figure 6: Estimates of Moderators of Word-of-Mouth 'Influence'

\section{'Influence' Coefficients}

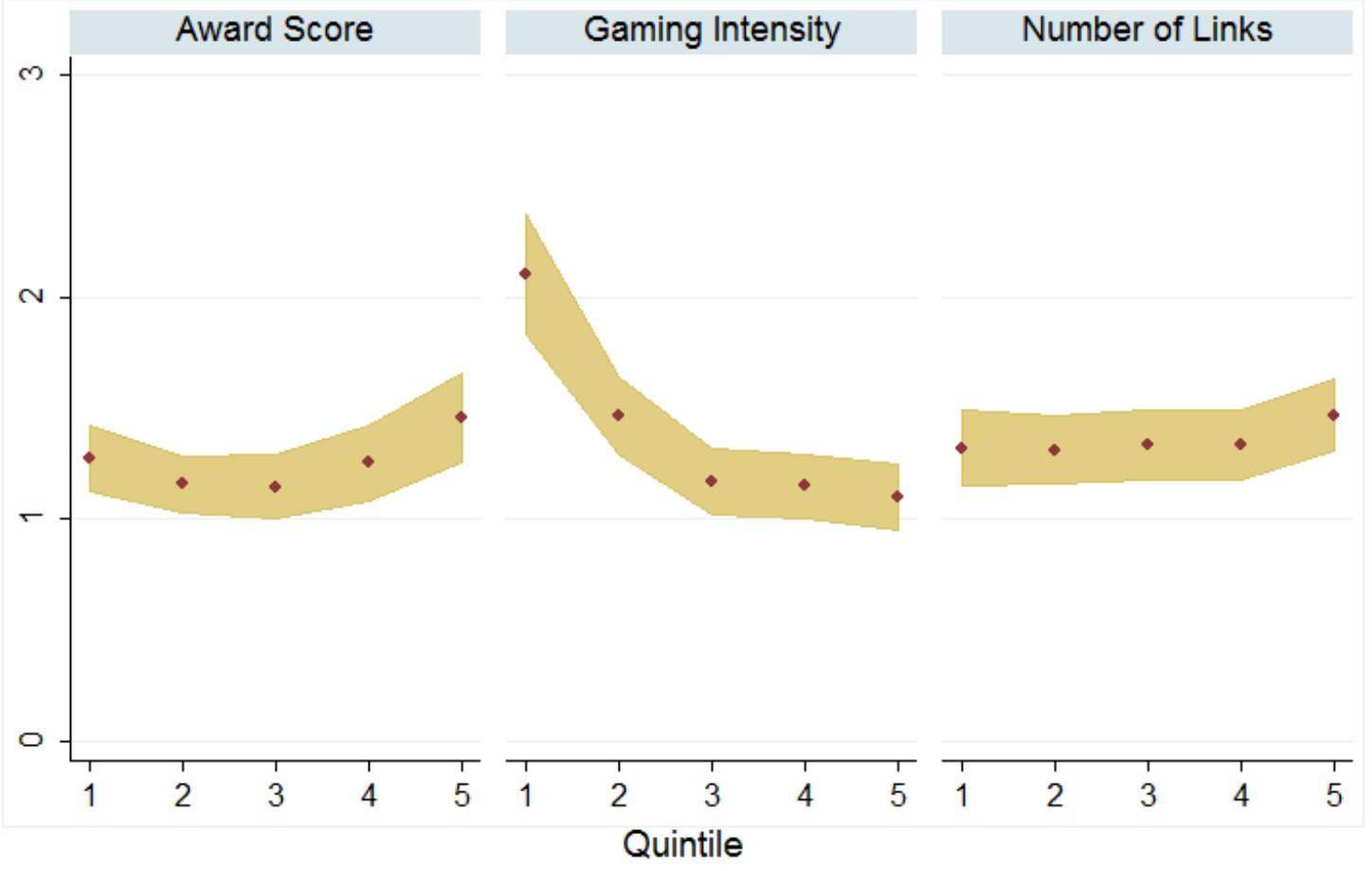

Coefficient and Two S.D. above and below 
Table 1: Summary Statistics

\begin{tabular}{llll}
\hline & $\begin{array}{c}\text { Focal } \\
\text { User } i\end{array}$ & \multicolumn{1}{c}{$\begin{array}{c}\mathrm{G} 1_{i} \\
\text { Members }\end{array}$} & \multicolumn{1}{c}{$\begin{array}{c}\mathrm{G} 2_{i} \\
\text { Members }\end{array}$} \\
\hline Game Adoption & 0.0406 & 0.0378 & 0.0272 \\
& $(0.1974)$ & $(0.1467)$ & $(0.0769)$ \\
Fraction of Time in Genre $\mathrm{g}$ & 0.1719 & 0.1762 & 0.1775 \\
& $(0.2481)$ & $(0.2154)$ & $(0.1762)$ \\
Fraction of Time in Platform $\mathrm{g}$ & 0.7952 & 0.7773 & 0.7722 \\
& $(0.3888)$ & $(0.3586)$ & $(0.3225)$ \\
Fraction of Time in ESRB $\mathrm{g}$ & 0.2622 & 0.2601 & 0.2586 \\
& $(0.3334)$ & $(0.2868)$ & $(0.2403)$ \\
Average Award Score & 0.4208 & 0.4231 & 0.4185 \\
& $(0.1894)$ & $(0.1554)$ & $(0.1187)$ \\
Ln Gaming Intensity & 5.3938 & 5.4910 & 5.6984 \\
& $(1.2880)$ & $(1.0595)$ & $(0.7459)$ \\
Ln Network Size & 1.2217 & 3.4952 & \\
& $(0.9620)$ & $(2.1480)$ & \\
\hline Averages and standard deviations (in parentheses) for 3,195,694 user by \\
game observations. The columns refer to values for the focal users, the \\
members of the G1, and the members of G2. \\
\hline
\end{tabular}


Table 2: Basic Regression Results (WOM = share G1 adopting)

\begin{tabular}{|c|c|c|c|c|}
\hline \multirow[b]{2}{*}{ Fraction of $i$ 's Time in Genre ${ }_{\mathrm{g}}$} & \multicolumn{2}{|c|}{$\begin{array}{c}\text { Fraction of } \mathrm{Gl}_{i} \\
\text { Adopting Game } g\end{array}$} & \multicolumn{2}{|c|}{ Did $i$ Adopt Game $g$} \\
\hline & $0.0027 * *$ & $(0.0004)$ & $0.0183 * *$ & $(0.0008)$ \\
\hline Fraction of $i$ 's Time in Platform $\mathrm{g}$ & $0.0019 * *$ & $(0.0004)$ & $0.0411^{* *}$ & $(0.0007)$ \\
\hline Fraction of $i$ 's Time in $\mathrm{ESRB}_{\mathrm{g}}$ & $0.0024 * *$ & $(0.0003)$ & $0.0177 * *$ & $(0.0006)$ \\
\hline Award Score $i$ & 0.0003 & $(0.0007)$ & $0.0111^{* *}$ & $(0.0013)$ \\
\hline Gaming Intensity $i$ & $-0.0002 * *$ & $(0.0001)$ & $-0.0031 * *$ & $(0.0002)$ \\
\hline Network Size $i$ & $0.0115^{* *}$ & $(0.0005)$ & $-0.0186^{* *}$ & $(0.0014)$ \\
\hline Fraction of $\mathrm{G} 1_{i}$ 's Time in Genre $\mathrm{g}$ & $0.0286^{* *}$ & $(0.0005)$ & $-0.0338 * *$ & $(0.0027)$ \\
\hline Fraction of $\mathrm{G} 1_{i}$ 's Time in Platform $\mathrm{g}$ & $0.0379 * *$ & $(0.0004)$ & $-0.0484 * *$ & $(0.0036)$ \\
\hline Fraction of $\mathrm{G}_{i}$ 's Time in $\mathrm{ESRB}_{\mathrm{g}}$ & $0.0251 * *$ & $(0.0004)$ & $-0.0310 * *$ & $(0.0024)$ \\
\hline Award Score $\mathrm{G} 1_{i}$ & -0.0010 & $(0.0009)$ & -0.0007 & $(0.0017)$ \\
\hline Gaming Intensity $\mathrm{G} 1_{i}$ & -0.0009 & $(0.0001)$ & $0.0012 * *$ & $(0.0003)$ \\
\hline Network Size $\mathrm{G} 1_{i}$ & $-0.0013 * *$ & $(0.0002)$ & $0.0016^{* *}$ & $(0.0004)$ \\
\hline Fraction of $\mathrm{G} 1_{i}$ Adopting Game $g$ & & & $1.4054 * *$ & $(0.0866)$ \\
\hline Fraction of $\mathrm{G} 2{ }_{i}$ 's Time in Genre $\mathrm{g}$ & $0.0026^{* *}$ & $(0.0008)$ & & \\
\hline Fraction of $\mathrm{G} 2_{i}{ }^{\prime}$ s Time in Platform $g$ & $0.0081 * *$ & $(0.0006)$ & & \\
\hline Fraction of $\mathrm{G}_{i}{ }^{\prime}$ 's Time in $\mathrm{ESRB}_{\mathrm{g}}$ & $0.0090 * *$ & $(0.0006)$ & & \\
\hline Award Score $\mathrm{G} 2_{i}$ & -0.0003 & $(0.0012)$ & & \\
\hline Gaming Intensity $\mathrm{G} 2_{i}$ & 0.0002 & $(0.0002)$ & & \\
\hline User $i$ Fixed Effects & $\mathrm{X}$ & & $\mathrm{X}$ & \\
\hline Game $g$ Fixed Effects & $X$ & & $\mathrm{X}$ & \\
\hline $\begin{array}{l}\text { The table reports the results of coe } \\
\text { game adoption decisions from } 3,1 \\
\text { and game fixed effects. Standard e }\end{array}$ & $\begin{array}{l}\text { from fir } \\
\text { bservati } \\
\text { parenthe }\end{array}$ & $\begin{array}{l}\text { secono } \\
\text { cluded }\end{array}$ & $\begin{array}{l}\text { es of an } \\
\text { lot repor } \\
p<0.01\end{array}$ & $\begin{array}{l}\text { egression } \\
\text { re both us }\end{array}$ \\
\hline
\end{tabular}


Table 3: Characteristics of Peers' Game Adoption

\begin{tabular}{lccc}
\hline & Observations & $\begin{array}{c}\text { Percent of } \\
\text { Sample }\end{array}$ & $\begin{array}{c}\text { Average } \\
\text { Fraction } \\
\text { Adopting }\end{array}$ \\
\hline No G1 $1_{i}$ Adoptions & & & 0.000 \\
Fraction of $1_{i}$ Adopting Game $g<0.273$ & $2,869,913$ & $89.8 \%$ & 0.148 \\
Fraction of $\mathrm{G} 1_{i}$ Adopting Game $g>0.273$ & 163,638 & $5.1 \%$ & 0.595 \\
\hline
\end{tabular}


Table 4: Basic Regression Results (WOM = any of G1 adopting)

\begin{tabular}{|c|c|c|c|c|}
\hline \multirow[b]{2}{*}{ Fraction of $i$ 's Time in Genre ${ }_{\mathrm{g}}$} & \multicolumn{2}{|c|}{$\begin{array}{c}\text { Any of } \mathrm{G} 1_{i} \\
\text { Adopting Game } g\end{array}$} & \multicolumn{2}{|c|}{ Did $i$ Adopt Game $g$} \\
\hline & $0.0101 * *$ & $(0.0008)$ & $0.0158 * *$ & $(0.0008)$ \\
\hline Fraction of $i$ 's Time in Platform $\mathrm{g}$ & $0.0077 * *$ & $(0.0007)$ & $0.0388 * *$ & $(0.0007)$ \\
\hline Fraction of $i$ 's Time in $\mathrm{ESRB}_{\mathrm{g}}$ & $0.0032 * *$ & $(0.0006)$ & $0.0195 * *$ & $(0.0006)$ \\
\hline Award Score $i$ & $0.0019 * *$ & $(0.0013)$ & $0.0105 * *$ & $(0.0012)$ \\
\hline Gaming Intensity $i$ & -0.0004 & $(0.0002)$ & -0.0031 & $(0.0002)$ \\
\hline Network Size $i$ & $0.1010 * *$ & $(0.0010)$ & $-0.0648 * *$ & $(0.0037)$ \\
\hline Fraction of $\mathrm{G} 1_{i}$ 's Time in Genre $\mathrm{g}$ & $0.0477 * *$ & $(0.0011)$ & $-0.0234 * *$ & $(0.0020)$ \\
\hline Fraction of $\mathrm{G} 1_{i}$ 's Time in Platform $\mathrm{g}$ & $0.0706 * *$ & $(0.0008)$ & $-0.0391 * *$ & $(0.0028)$ \\
\hline Fraction of $\mathrm{G}_{i}$ 's Time in $\mathrm{ESRB}_{\mathrm{g}}$ & $0.0366 * *$ & $(0.0008)$ & $-0.0177 * *$ & $(0.0016)$ \\
\hline Award Score $\mathrm{G} 1_{i}$ & $-0.0052 *$ & $(0.0017)$ & 0.0014 & $(0.0016)$ \\
\hline Gaming Intensity $\mathrm{G} 1_{i}$ & 0.0020 & $(0.0003)$ & $-0.0013 * *$ & $(0.0002)$ \\
\hline Network Size $\mathrm{G} 1_{i}$ & -0.0001 & $(0.0004)$ & 0.0000 & $(0.0003)$ \\
\hline Any of $\mathrm{G} 1_{i}$ Adopting Game $g$ & & & $0.6171 * *$ & $(0.0357)$ \\
\hline Fraction of $\mathrm{G} 2{ }_{i}$ 's Time in Genre $\mathrm{g}$ & $0.0098 * *$ & $(0.0016)$ & & \\
\hline Fraction of $\mathrm{G} 2_{i}{ }^{\prime}$ s Time in Platform $g$ & $0.0206^{* *}$ & $(0.0011)$ & & \\
\hline Fraction of $\mathrm{G}_{i}{ }^{\prime}$ 's Time in $\mathrm{ESRB}_{\mathrm{g}}$ & $0.0152 * *$ & $(0.0011)$ & & \\
\hline Award Score $\mathrm{G} 2_{i}$ & $-0.0066^{*}$ & $(0.0024)$ & & \\
\hline Gaming Intensity $\mathrm{G} 2_{i}$ & $-0.0021 * *$ & $(0.0004)$ & & \\
\hline User $i$ Fixed Effects & $X$ & & $X$ & \\
\hline Game $g$ Fixed Effects & $X$ & & $\mathrm{X}$ & \\
\hline $\begin{array}{l}\text { The table reports the results of coe } \\
\text { game adoption decisions from } 3,1 \\
\text { and game fixed effects. Standard e }\end{array}$ & $\begin{array}{l}\text { from fir } \\
\text { bservatic } \\
\text { parenthe }\end{array}$ & $\begin{array}{l}\text { secono } \\
\text { cluded } \\
\mathrm{p}<0.0\end{array}$ & $\begin{array}{l}\text { es of an } \\
\text { lot report } \\
p<0.01\end{array}$ & $\begin{array}{l}\text { egression } \\
\text { re both us }\end{array}$ \\
\hline
\end{tabular}




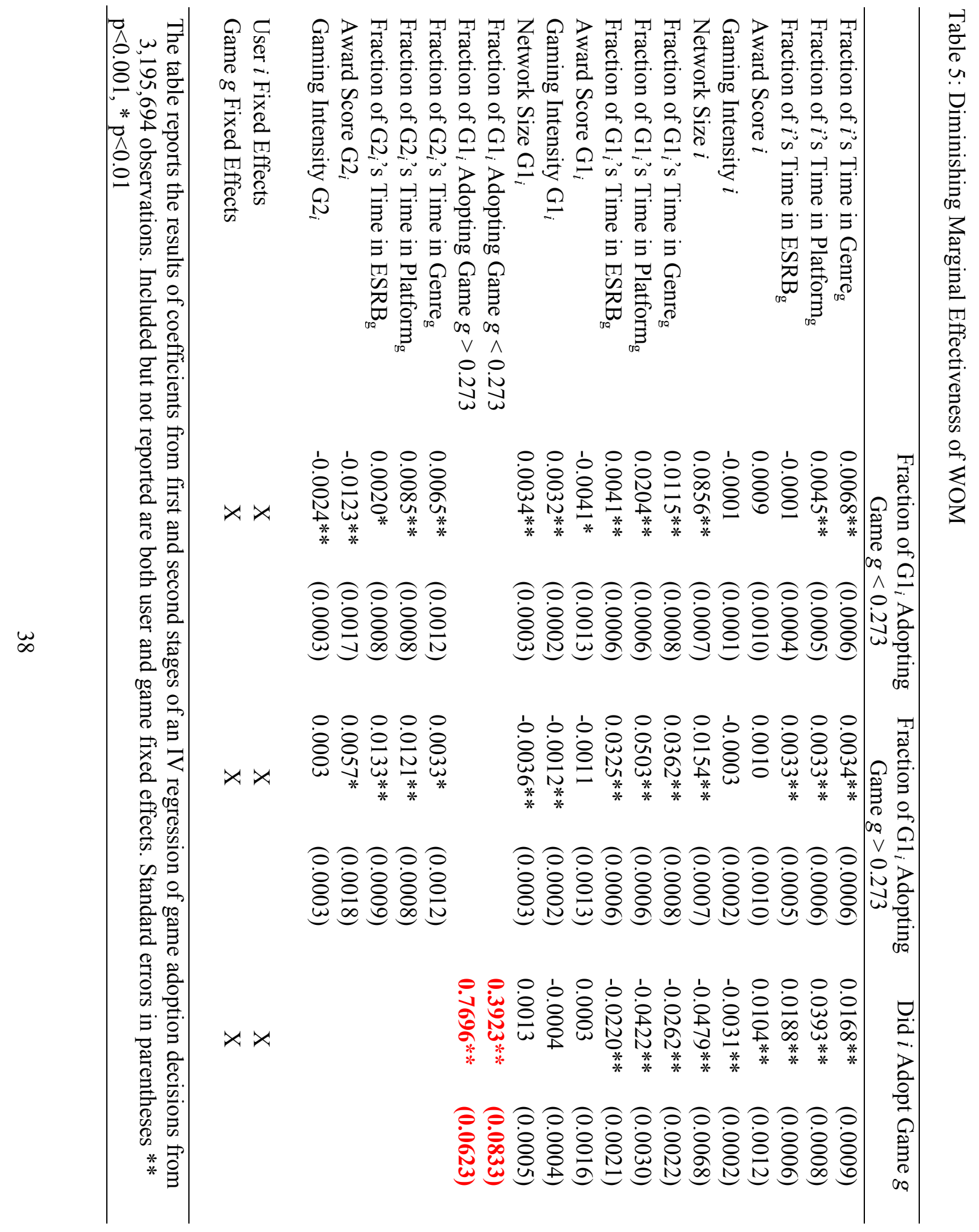




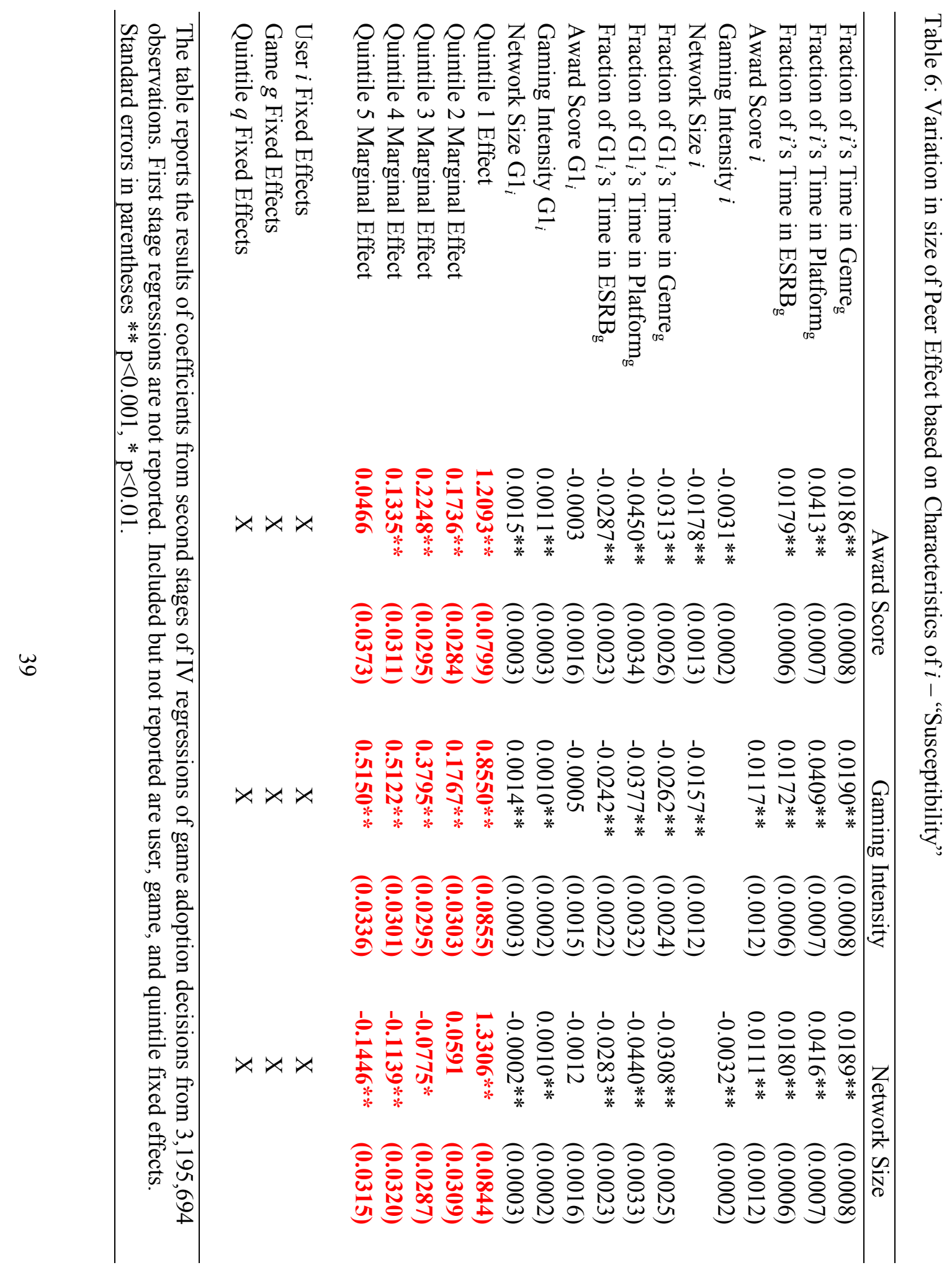




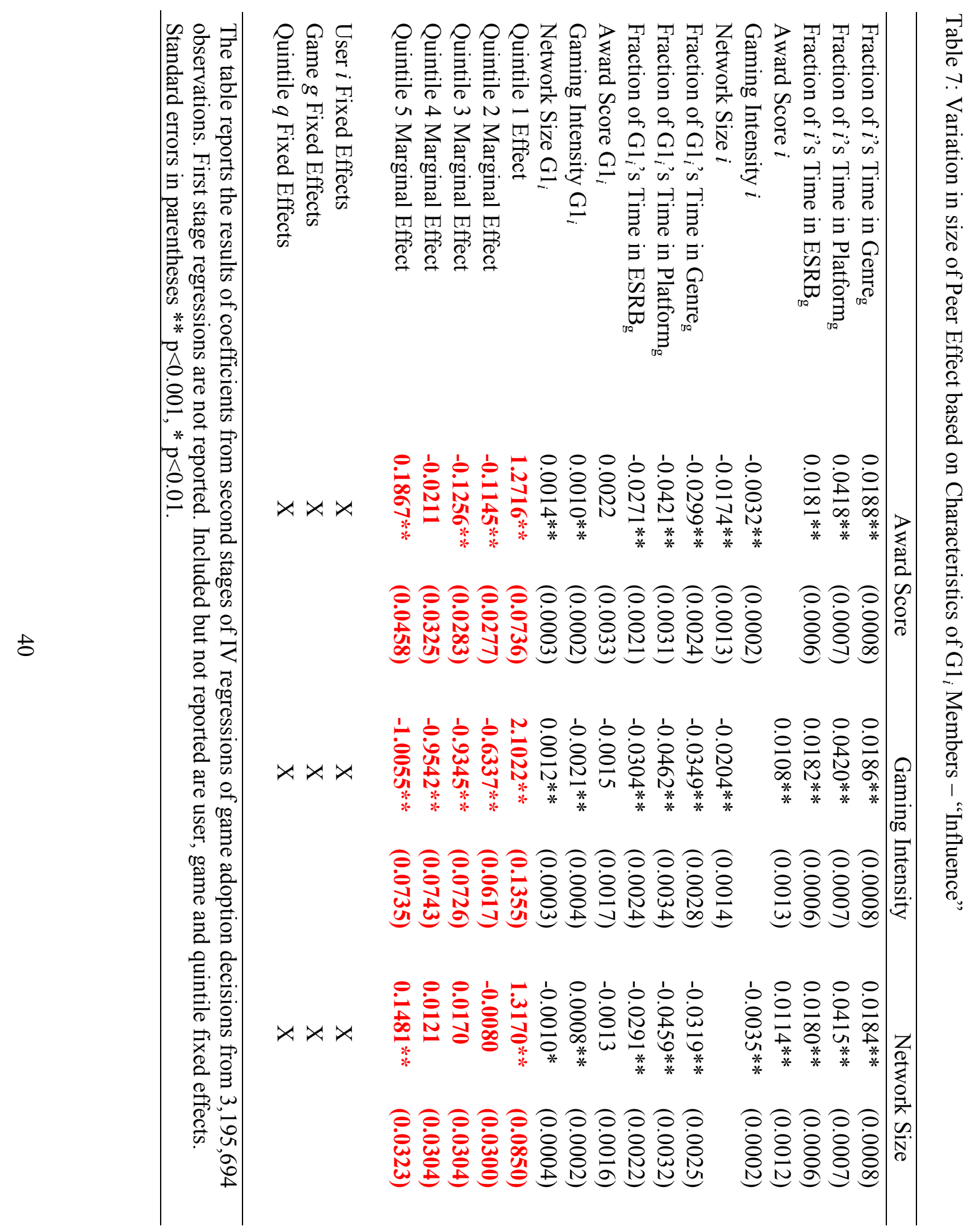

